\title{
Effects of dietary fat on insulin secretion in subjects with the metabolic syndrome
}

\author{
Hanne L Gulseth ${ }^{1,2,3}$, Ingrid M F Gjelstad ${ }^{1,2}$, Audrey C Tiereny 4,5,6, Danielle McCarthy7,8, Julie A Lovegrove ${ }^{7,9}$, \\ Catherine Defoort ${ }^{10}$, Ellen E Blaak ${ }^{11}$, Jose Lopez-Miranda ${ }^{12}$, Aldona Dembinska-Kiec ${ }^{13}$, Ulf Risérus ${ }^{14}$, \\ Helen M Roche ${ }^{4}$, Christian A Drevon ${ }^{2}$ and Kåre I Birkeland ${ }^{1,15}$
}

${ }^{1}$ Department of Endocrinology, Morbid Obesity and Preventive Medicine, Oslo University Hospital and Faculty of Medicine, University of Oslo, Oslo, Norway, ${ }^{2}$ Department of Nutrition, Institute of Basic Medical Sciences, Faculty of Medicine, University of Oslo, Oslo, Norway, ${ }^{3}$ Department of Chronic Diseases and Ageing, Norwegian Institute of Public Health, Oslo, Norway, ${ }^{4}$ Nutrigenomics Research Group, UCD Conway Institute \& UCD Institute of Food and Health, School of Public Health, Physiotherapy and Sports Science, University College Dublin, Dublin, Ireland, ${ }^{5}$ School of Allied Health, University of Limerick, Limerick, Ireland, ${ }^{6}$ School of Allied Health, La Trobe University, Bundoora, Melbourne, Australia, 7 The Hugh Sinclair Unit of Human Nutrition, Department of Food Biosciences, University of Reading, Reading, UK, IInstitute for Global Food Security, Northern Ireland Technology Centre, Queen's University Belfast, Belfast, Northern Ireland, ${ }^{9}$ Institute for Cardiovascular and Metabolic Research, University of Reading, Reading, UK, ${ }^{10} \mathrm{C} 2 \mathrm{VN}$, INRA, INSERM, Aix Marseille Univ, Marseille, France, ${ }^{11}$ NUTRIM, School for Nutrition, Toxicology and Metabolism, Maastricht University Medical Centre, Maastricht, the Netherlands, ${ }^{12}$ Lipids and Atherosclerosis Research Unit, Instituto Maimonides de Investigacion Biomedica de Córdoba (IMIBIC)/Hospital Universitario Reina Sofia/Universidad de Cordoba and CIBER Fisiopatologia Obesidad y Nutricion (CIBEROBN), Instituto de Salud Carlos III, Madrid, Spain, ${ }^{13}$ Department of Clinical Biochemistry, Jagiellonian University Medical College, Krakow, Poland, ${ }^{14}$ Department of Public Health and Caring Sciences/Clinical Nutrition and Metabolism, Uppsala University, Uppsala, Sweden, and ${ }^{15}$ Institute of Clinical Medicine, Faculty of Medicine, University of Oslo, Oslo, Norway

Correspondence should be addressed to H L Gulseth Email

h.l.gulseth@medisin.uio.no

\begin{abstract}
Objective: Impaired insulin secretion and action contribute to the development of type 2 diabetes. Dietary fat modification may improve insulin sensitivity, whereas the effect on insulin secretion is unclear. We investigated the effect of dietary fat modification on insulin secretion in subjects with the metabolic syndrome.

Design: In a 12-week pan-European parallel, randomized controlled dietary intervention trial (LIPGENE), 486 subjects were assigned to four isoenergetic diets: high-fat diets rich in saturated fat (HSFA) or monounsaturated fat (HMUFA) or low-fat, high-complex carbohydrate diets with (LFHCC $n$-3) or without (LFHCC control) $1.2 \mathrm{~g} /$ day of $n$-3 PUFA supplementation. Insulin secretion was estimated as acute insulin response to glucose (AIRg) and disposition index (DI), modeled from an intravenous glucose tolerance test.

Results: There were no overall effect of the dietary intervention on AIRg and DI in the total cohort, in neither the highfat nor LFHCC groups. We observed significant diet*fasting glucose category interactions for $\operatorname{AIRg}(P=0.021)$ and $\mathrm{DI}$ $(P=0.001)$ in the high-fat groups. In subjects with normal fasting glucose and preserved first phase insulin secretion, the HMUFA diet increased, whereas the HSFA diet reduced AIRg $(P=0.015)$ and $\mathrm{DI}(P=0.010)$. Conclusions: The effects of dietary fat modification on insulin secretion were minor, and only evident in normoglycemic subjects. In this case, the HMUFA diet improved AIRg and DI, as compared to the HSFA diet.
\end{abstract}

\section{Introduction}

Subjects with the metabolic syndrome have insulin resistance and increased risk of insulin secretory dysfunction and type 2 diabetes $(1,2)$. Loss of insulin secretion is linked to the development of impaired glucose tolerance and type 2 diabetes (3) and $\beta$-cell dysfunction may predict who, among subjects with insulin resistance, eventually will develop impaired glucose tolerance or type 2 diabetes $(4,5,6,7,8,9)$. In the Diabetes Prevention

Published by Bioscientifica Ltd. 
Program, as well as in the Finnish Diabetes Prevention Study, lifestyle modifications with diet and exercise reduced the risk of developing type 2 diabetes $(10,11)$, and also showed beneficial effects on the prevalence and features of the metabolic syndrome $(12,13)$.

Dietary macronutrient composition may influence insulin sensitivity $(14,15,16,17)$, but little is known about the effect on insulin secretion (18). Carbohydrate modification improved insulin secretion measured as the insulinogenic index in subjects with the metabolic syndrome (19), whereas substituting dietary saturated fat (SFA) for monounsaturated fat (MUFA) in the KANWU study attenuated the reduction in insulin sensitivity, but did not affect insulin secretion in healthy subjects (20). In contrast, a cross-sectional study from Spain suggested a favorable relationship of MUFA with insulin secretion based on fasting measurements of glucose and insulin (homeostasis model of insulin secretion (HOMA $\beta$ )) (21). In the long-term prospective CODAM cohort study, dietary MUFA intake was also associated with improved $\beta$-cell glucose sensitivity (22). The long-term effects of polyunsaturated fatty acids (PUFAs) on insulin secretion in humans are sparsely investigated, although one study showed no beneficial effect of fish oil supplementation regardless of habitual dietary intake of $n-3$ and $n-6$ (23). A more recent meta-analyses of feeding trials however showed that PUFA could have beneficial effects on insulin secretory capacity whether replacing carbohydrate, SFA or MUFA (24).

In the present study, we investigated the impact of an isoenergetic change in dietary fat quantity and quality on insulin secretion in a large European sample of subjects with the metabolic syndrome.

\section{Subjects and methods}

The LIPGENE study was a clinical 12 weeks parallel, randomized controlled dietary intervention trial, performed in eight European centers as part of the $\mathrm{EU} 6^{\text {th }}$ Framework integrated project 'Diet, genomics and the metabolic syndrome - LIPGENE' (http://www.ucd.ie/lipgene/). Randomization was completed centrally, stratified for age, sex and fasting plasma glucose concentration using the MINIM program (MINIM: allocation by minimization in clinical trials, Evans S, Royston P and Day S, Dept of Clinical Epidemiology, The London Hospital Medical College, UK) (25). The study was approved by local ethics committees at each of the eight intervention centers (Dublin, Reading, Oslo, Marseille, Maastricht, Cordoba,
Krakow and Uppsala) and conformed to the Declaration of Helsinki. Written informed consent was obtained from all study participants. The study was registered with the US National Library of Medicine Clinical Trials registry (NCT00429195). The primary endpoint was to determine the effect of dietary fat modification on insulin sensitivity, and these results have been reported previously (26). The effects of the intervention on insulin secretion were a prespecified secondary endpoint.

\section{Subjects}

Study participants, Caucasian males and females aged 35-70 years with BMI $20-40 \mathrm{~kg} / \mathrm{m}^{2}$, had the metabolic syndrome as defined by three or more of the following slightly modified NCEP ATP-III criteria (27). Levels of fasting plasma glucose $>5.5 \mathrm{mmol} / \mathrm{L}$, triglycerides $\geq 1.5 \mathrm{mmol} / \mathrm{L}$, HDL-cholesterol $<1.0 \mathrm{mmol} / \mathrm{L}$ (males) or $<1.3 \mathrm{mmol} / \mathrm{L}$ (females), systolic blood pressure (BP) $\geq 130 \mathrm{mmHg}$ or diastolic $\mathrm{BP} \geq 85 \mathrm{mmHg}$ (or BP lowering medication) and waist circumference $>102 \mathrm{~cm}$ (males) or $>88 \mathrm{~cm}$ (females). Antihypertensive medication, hormone replacement therapy, multivitamin supplements and nonfatty acid-based nutritional supplements were allowed if the subject adhered to the same regimen throughout the study. Exclusion criteria included pre-diagnosed diabetes, inflammatory diseases, use of statins and antiinflammatory drugs, fatty acid supplements, alcohol abuse and a recent weight change $\geq 3 \mathrm{~kg}$. A total of 486 subjects attended the pre-intervention investigational day, 417 participants completed the study and 404 subjects had a post-intervention intravenous glucose tolerance test (IVGTT) performed.

\section{Diets}

Subjects were randomly assigned to one of four isoenergetic diets differing in fat quantity or quality as previously described (28). In short, two high-fat diets provided 38\% energy (E\%) from fat: one with a high content (16 E\%) of SFA (HSFA diet) and one with a high content (20 E\%) of MUFA (HMUFA diet) and two low-fat, high-complex carbohydrate (LFHCC) diets contained $28 \mathrm{E} \%$ from fat, with diet LFHCC $n$-3 including $1.2 \mathrm{~g} /$ day supplement of very long-chain marine $n-3$ polyunsaturated fatty acids (VLC $n$-3 PUFA) and diet LFHCC control including a control high-oleic acid sunflower-seed oil capsule (Lipid Nutrition, Loders Croklaan, Wormerveer, The Netherlands). Dietary targets are presented in Table 1. A food exchange model was developed, and fat-modified food products (margarines, 
Table 1 Dietary intake at baseline and after 12 weeks of dietary intervention with aims for adjustments of fat intake in bold. Data are presented as energy (\%) or as indicated. Values represent means (S.D.).

\begin{tabular}{|c|c|c|c|c|c|c|c|c|c|}
\hline & \multirow[b]{2}{*}{ Baseline } & \multicolumn{8}{|c|}{ Post-intervention } \\
\hline & & Aim & HSFA & Aim & MUFA & Aim & LFHCC control & Aim & LFHCC n-3 \\
\hline$n$ & 403 & & 86 & & 101 & & 91 & & 90 \\
\hline Energy, MJ & $8.9(2.6)$ & & $8.7(2.5)$ & & $8.8(2.6)$ & & $8.3(3.1)$ & & $8.3(1.4)$ \\
\hline Carbohydrate, E (\%) & $43.9(7.5)$ & & $41.5(6.5)$ & & $41.5(6.1)$ & & $49.5(8.0)$ & & $50.0(7.0)$ \\
\hline Protein, E (\%) & $17.6(3.9)$ & & $17.4(4.2)$ & & $17.1(3.5)$ & & $18.9(5.0)$ & & $18.5(4.0)$ \\
\hline Fat, E (\%) & $35.8(7.3)$ & 38 & $39.5(6.0)$ & 38 & $39.0(5.3)$ & 28 & $29.5(6.4)$ & 28 & $29.3(5.2)$ \\
\hline SFA, E (\%) & $12.4(3.2)$ & 16 & $17.3(3.1)$ & 8 & $10.4(2.0)$ & 8 & $8.6(2.6)$ & 8 & $8.8(2.6)$ \\
\hline MUFA & $13.4(4.8)$ & 12 & $12.6(2.6)$ & 20 & $18.9(3.7)$ & 11 & $11.8(3.2)$ & 11 & $11.4(2.8)$ \\
\hline PUFA & $5.6(2.2)$ & 6 & $6.1(1.6)$ & 6 & $6.6(1.6)$ & 6 & $6.0(1.9)$ & 6 & $5.7(1.4)$ \\
\hline EPA and DHA (g/day)* & $0.34(0.54)$ & & $0.23(0.32)$ & & $0.33(0.52)$ & & $0.36(0.52)$ & & $1.64(0.56)$ \\
\hline Alcohol & $2.3(4.1)$ & & $1.7(2.6)$ & & $2.2(3.8)$ & & $2.0(3.1)$ & & $2.2(3.9)$ \\
\hline
\end{tabular}

$\star_{n}=\mathrm{x}, 71,79,79$ and 76 , respectively.

DHA, docosahexaenoic acid; EPA, eicosapentaenoic acid; HMUFA, high-fat diet rich in monounsaturated fat; HSFA, high-fat diet rich in saturated fat; LFHCC control, low-fat, high-complex carbohydrate diet with control supplement; LFHCC-n-3, low-fat, high-complex-carbohydrate diet with very long-chain n-3 PUFA supplement.

cooking and baking fats, oils, dressings and biscuits) were supplied by Unilever (Vlaardingen, The Netherlands). All participants completed a 3-day weighed food record and a food frequency questionnaire (FFQ) to estimate the dietary intake. Food records were also completed midand post-intervention to assess compliance. Nutrient composition was calculated using center-specific dietary analysis programs, including the nutrient composition of the LIPGENE intervention foods. To ensure adherence to the diets, the dietitians/nutritionists regularly, at least every other week, contacted the participants for 24-h diet recalls and completion of food use questionnaires. All diets were isoenergetic and investigators monitored subjects' weight during the intervention period with the aim of maintaining weight.

\section{Clinical assessment}

Health status was screened by medical history and routine laboratory measurements. A questionnaire was used to monitor each subject's level of physical activity, measured as total Baecke score (29), smoking habits, alcohol consumption and demographic data. Anthropometric measurements were recorded according to standard protocols. Weight and height were measured to the nearest $0.1 \mathrm{~kg}$ and $0.1 \mathrm{~cm}$, respectively. Waist circumference was recorded at the midpoint between the lowest rib and the iliac crest to the nearest $0.1 \mathrm{~cm}$. BMI was calculated as weight $(\mathrm{kg}) /$ height $^{2}\left(\mathrm{~m}^{2}\right)$. BP was measured using an automatic BP measuring device following the European Society of Hypertension Guidelines (30). Measurement was performed with an appropriately sized cuff positioned at the heart level and the patient had been relaxed for minimum $5 \mathrm{~min}$. At least two measurements were performed, and the average used for data processing.

\section{Insulin action and secretion}

An insulin-modified IVGTT was performed as described prior (31). After an overnight fast, a catheter was inserted into an antecubital vein for blood sampling and into a contralateral antecubital vein for glucose and insulin injection. At time $0 \mathrm{~min}$, glucose $(0.3 \mathrm{~g} / \mathrm{kg}$ bodyweight $)$ was given intravenously, and after $20 \mathrm{~min}$ a bolus of $0.03 \mathrm{IU} / \mathrm{kg}$ of human insulin (Actrapid, NovoNordisk) was injected. Blood samples were drawn at $-5,0,2,4,8,19$, 22, 30, 40, 50, 70, 90 and $180 \mathrm{~min}$. Measures of insulin sensitivity $\left(\mathrm{S}_{\mathrm{I}}\right)$ were determined using the MINMOD Millennium Program (version 6.02, Richard N Bergman) (32). The acute insulin response to glucose $(A I R g=$ first phase insulin response) was defined as the incremental area under the curve from time 0 to $8 \mathrm{~min}$. DI was calculated as the product of AIRg and $\mathrm{S}_{\mathrm{I}}$ and was determined for the 330 subjects with complete pre and post $\mathrm{S}_{\mathrm{I}}$ modeling as carried out with the MINMOD program.

\section{Biochemical analyses}

Plasma insulin concentrations were determined using a human immunometric assay kit (AutoDELFIA Insulin, Perkin Elmer Life Sciences) on a 1235 automatic immunoassay system (Wallac 1235 AutoDELFIA, Wallac Oy, Turku, Finland). Plasma total cholesterol, HDLcholesterol, LDL-cholesterol, triacylglycerol (TAG) and glucose concentrations were determined with an ILAB 600 clinical chemical analyzer using enzymatic colorimetric 
kits (Instrumentation Laboratory, Warrington, UK). HDL-cholesterol and LDL-cholesterol were isolated using relevant kits (HDL-cholesterol kit, Instrument Laboratory, Warrington, UK and CH1350 Randox Laboratories Ltd, Antrim, UK).

\section{Statistical methods}

Baseline data are presented as group means and standard deviations (s.D.), and changes in biological parameters are given as mean per group and 95\% CI. Differences between baseline parameters were investigated using ANOVA, non-parametric alternative Kruskal-Wallis and the chi-square test for categorical variables as appropriate. General linear models (two-way ANCOVA) were used to assess differences in post-intervention parameter between groups, adjusted for baseline parameter and potential confounders (age, sex, center and BMI) (33). Correlations between parameters were calculated with Spearman's correlation coefficients. A two-sided $P$ value $<0.05$ was regarded significant. Analyses were performed using SPSS for Windows 24.0 (SPSS Inc) and R 2.8.0 (R foundation for Statistical Computing, Vienna, Austria).

\section{Results}

\section{Baseline characteristics of the study subjects}

Clinical characteristics of the 408 study participants (diet HSFA $n=95$, diet HMUFA $n=109$, diet LFHCC control $n=103$ and diet LFHCC n-3 $n=101$ ) with available baseline IVGTT modeling are described in Table 2; there were no differences between the dietary groups in baseline characteristics. The mean age was $54.4 \pm 9.0$ years, $45 \%$ were males, the mean BMI was $32.3 \pm 4.1 \mathrm{~kg} / \mathrm{m}^{2}$ and only ten subjects had BMI $<25 \mathrm{~kg} / \mathrm{m}^{2}$. Baseline parameters of insulin secretion (AIRg and DI) did not differ between completers and non-completers, and the non-completers were evenly distributed between dietary groups. In our cohort 33\% were normoglycaemic (fasting p-glucose $<5.6 \mathrm{mmol} / \mathrm{L}$ ), $57 \%$ had impaired fasting glucose (fasting p-glucose $5.6-7.0 \mathrm{mmol} / \mathrm{L}$ ) and $10 \%$ had fasting glucose values $\geq 7.0 \mathrm{mmol} / \mathrm{L}$. First phase insulin secretion at baseline declined across categories of fasting p-glucose, and there were significant differences between categories of fasting p-glucose for AIRg $(P<0.001)$ and DI $(P<0.001)$. $S_{\mathrm{I}}$ did not differ $(P=0.36)$

\section{Effects on insulin secretion}

In the total cohort, there were no significant differences in the effects of the intervention on AIRg or DI between all dietary groups, nor between the two high-fat dietary groups or the two LFHCC diets (all P>0.05) (Table 3).

As insulin secretion differed across categories of fasting plasma glucose, we tested whether insulin secretion differed between groups in normoglycaemic individuals. We demonstrated a significant interaction between diet group and fasting p-glucose category for the HMUFA versus the HSFA diet for both AIRg $(P=0.021)$ and DI $(P=0.001)$. In subjects with normal fasting p-glucose $<5.6 \mathrm{mmol} / \mathrm{L}$, insulin secretion was lower after the HSFA diet compared

Table 2 Means (S.D.) or percentages of baseline clinical characteristics across dietary groups. Values represent means (S.D.). There were no significant differences between dietary groups at baseline in an ANOVA test.

\begin{tabular}{lcc} 
& HSFA \\
\cline { 1 - 1 } Age (years) & 95 \\
Sex (\% males) & $54.2(8.6)$ \\
BMI (kg/m²) & 53 \\
Waist circumference & & $32.0(4.3)$ \\
Body fat* & & $36.9(9.7)$ \\
F-plasma glucose (mmol/L) & $6.0(0.8)$ \\
F-triacylglycerol (mmol/L) & & $2.0(1.1)$ \\
HDL-cholesterol & & $1.04(0.24)$ \\
LDL-cholesterol & $3.2(1.0)$ \\
Total cholesterol & $5.3(0.8)$ \\
Smoke (\% yes) & 35 \\
Physical activity (AU) ${ }^{\dagger}$ & $7.6(1.2)$ \\
\hline
\end{tabular}

\begin{tabular}{c}
\hline HMUFA \\
\hline 109 \\
$54.9(8.7)$ \\
45 \\
$32.7(4.2)$ \\
$106.8(11.2)$ \\
$36.8(8.5)$ \\
$5.9(0.7)$ \\
$1.8(0.8)$ \\
$1.09(0.29)$ \\
$3.1(1.0)$ \\
$5.3(0.9)$ \\
28 \\
$7.7(1.3)$ \\
\hline
\end{tabular}

\begin{tabular}{c}
\hline LFHCC control \\
\hline 103 \\
$54.1(9.3)$ \\
48 \\
$32.0(4.3)$ \\
$107.0(11.2)$ \\
$36.6(8.5)$ \\
$6.0(0.8)$ \\
$1.8(0.9)$ \\
$1.09(0.28)$ \\
$3.2(1.0)$ \\
$5.3(1.0)$ \\
29 \\
$7.7(1.1)$ \\
\end{tabular}

\begin{tabular}{c}
\hline LFHCC $\mathbf{n}-\mathbf{3}$ \\
\hline 101 \\
$54.8(9.9)$ \\
47 \\
$32.5(4.1)$ \\
$106.4(9.9)$ \\
$36.3(9.0)$ \\
$5.9(0.9)$ \\
$1.8(0.9)$ \\
$1.11(0.29)$ \\
$3.4(1.1)$ \\
$5.4(0.9)$ \\
37 \\
$7.7(1.2)$
\end{tabular}

${ }^{*} n=91,105,101$ and 96 , respectively. ${ }^{\dagger} n=66,78,74$ and 77 , respectively.

$\mathrm{AU}$, arbitrary unit of physical activity; HMUFA, high-fat diet rich in monounsaturated fat; HSFA, high-fat diet rich in saturated fat; LFHCC control, low-fat, high-complex-carbohydrate diet with control supplement; LFHCC-n-3, low-fat, high-complex-carbohydrate diet with very long-chain n-3 PUFA supplement. 
Table 3 Adjusted means and 95\% Cl for acute insulin response to glucose (AIRg) and disposition index (DI) at baseline and end of intervention. All values represent adjusted means (age, sex, center and BMI) and 95\% confidence intervals. Analysis of covariance model with adjustment for baseline value of the respective values including age, sex, center and BMI.

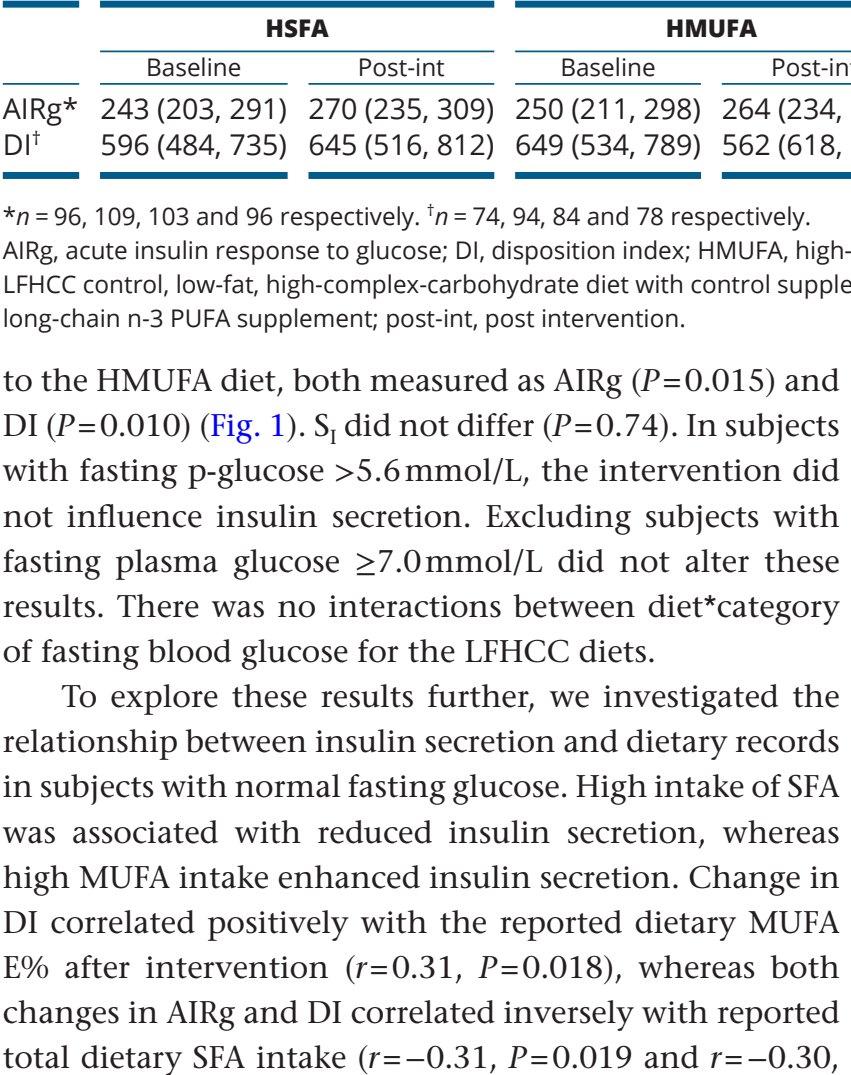

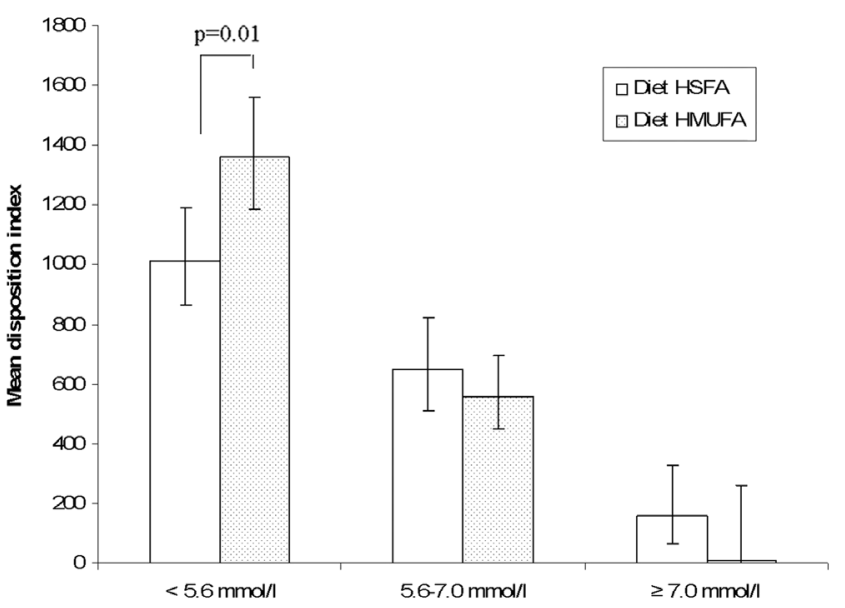

\section{Figure 1}

Means (95\% Cl) disposition index (DI) after intervention, adjusted for baseline DI, age, sex, center and BMI in the high-fat diet rich in saturated fat $\square(n=35)$, and the high-fat diet rich in monounsaturated fat $\because(n=26)$. P value: Analysis of covariance model with adjustment for baseline value of the respective value, age, sex, center and BMI.
$P=0.02$, respectively). In addition, the dietary intake of individual saturated fatty acids (12:0, 14:0, 16:0, 18:0) post intervention correlated inversely with changes in both AIRg and DI (all $P<.03$ ).

\section{Dietary records and body weight}

Dietary composition at baseline was similar between diets, and dietary intakes at baseline and at the end of intervention are presented in Table 1. Dietary compositional targets were achieved with aimed differences in fat quantity between the high-fat and the low-fat diets and in fat quality between the HSFA and HMUFA diets (28). Body weight remained unchanged in the two high-fat dietary groups, but was slightly reduced on the two low-fat diets (LFHCC control: -0.9 (95\% CI -1.3, -0.6) $\mathrm{kg}$ and LFHCC n-3: -0.7 (95\% CI -1.0, -0.3) kg) (26).

\section{Discussion}

In the present isoenergetic intervention study, we found no major effects of intervention in dietary fat quantity and quality on insulin secretion in a population of subjects with the metabolic syndrome and high risk of developing type 2 diabetes. However, the metabolic syndrome is a very heterogeneous classification, and to this end, we report interesting preliminary findings wherein the impact of a dietary intervention may depend, in part, on the baseline glycemic status of the cohort. The findings are in line with a small, randomized cross-over trial in eight healthy young males, reporting no effect of dietary fatty acid saturation on IVGTT-estimated insulin secretion (34). Also in an epidemiological study among Swedish women, there were no correlations between insulin secretory variables and habitual dietary fat intake (35). In the KANWU study, no effects on AIRg (20) or DI (23) were observed. The diets in the KANWU study were comparable to the HSFA and HMUFA diets in LIPGENE 
study, and the study design was similar, although the mean plasma glucose was $5.2 \mathrm{mmol} / \mathrm{L}$ in $\mathrm{KANWU}$ and $6.0 \mathrm{mmol} / \mathrm{L}$ in the LIPGENE study.

First-phase insulin secretion was significantly reduced in LIPGENE participants with elevated fasting glucose, as expected and previously reported $(36,37)$. Hence, it may be expected that only the group with normal fasting glucose and preserved first-phase insulin secretion showed effect of the dietary intervention on insulin secretion. In this subgroup, there was a small, but significant detrimental effect of a SFA enriched diet as compared to a high MUFA diet. Thus, with regard to $\beta$-cell function, subjects with normal glucose levels may be more sensitive to dietary fat modification. Consistent with our results, Rojo-Martínez et al. reported an association between MUFA and improved insulin secretion in a population-based study (21). Meal studies have also shown a beneficial effect on $\beta$-cell function of MUFA compared to SFA $(38,39)$. Acute stimulatory effects of fatty acids on glucose-stimulated insulin secretion have been demonstrated both in vitro and in vivo (18). In eight healthy volunteers the effect of dietary fatty acid quality was investigated and MUFA proved to have the greatest increase in glucose-stimulated insulin secretion measured during hyperglycemic clamp (40). The mechanisms responsible for these differential effects of diets rich in SFA and MUFA are unclear. One possibility is an effect via the incretin system, as MUFA, but not SFA, has been shown to enhance GLP-1 secretion (38, 41). GLP-1 responses were not measured in the present study as insulin secretory response was studies after intravenous rather than after oral glucose exposure.

It has also been proposed that high daily intake of SFA in genetically prone subjects might lead to type 2 diabetes due to lipotoxicity. Accumulation of intramyocytic TAG may decrease insulin-stimulated glucose uptake and impair glucose oxidation, whereas large TAG stores in pancreatic $\beta$-cells may promote reduced insulin secretion (18). Especially palmitic acid has been shown to be lipotoxic and induce ER stress $(42,43)$.

We did not find an effect of marine omeaga-3 fatty acid supplementation of insulin secretion during low-fat diets, which is in accordance with previous controlled studies $(34,41)$. We cannot exclude the possibility that larger doses of n-3 PUFA supplementation than we used $(1.2 \mathrm{~g} /$ day $)$ or longer duration might have an effect.

The IVGTT is a sensitive tool (44) to assess insulin secretion as loss of function usually is seen well before diabetes or even impaired glucose tolerance develops. However, the IVGTT may not be an optimal method for measuring insulin secretion in subjects with hyperglycemia as the first-phase insulin secretion (AIRg) often vanishes above fasting p-glucose concentrations $>7.0 \mathrm{mmol} / \mathrm{L}$ (37). Pre-diagnosed diabetes mellitus was an exclusion criterion for the LIPGENE study, still 37 participants had a fasting p-glucose $\geq 7.0 \mathrm{mmol} / \mathrm{L}$ when tested. We did not perform oral glucose tolerance tests; thus, most likely there are even more cases of undiagnosed type 2 diabetes subjects in our cohort. Another limitation of the IVGTT method as compared to the OGTT is that it does not assess incretininduced insulin secretion.

The LIPGENE study is one of the largest dietary intervention studies carried out in subjects with obesity and a dysmetabolic profile. With subjects from Northern, Southern, Eastern and Western Europe, the dietary interventions were implemented in a heterogeneous dietary background. The dietary intakes, as assessed by weighed food records, were achieved with significant differences in fat quantity and quality between diets (28). However, lack of overall dietary effects due to poor adherence to the diets cannot be excluded. The study was designed to be isoenergetic and the subjects should not lose weight. Body weight did not change in the highfat dietary groups, but there was a small and statistically significant weight loss of $<1 \mathrm{~kg}$ in the low-fat groups. The primary endpoint of the LIPGENE study was insulin sensitivity; therefore, power calculations did not include estimates of insulin secretion, which limit the impact of the present analysis.

In conclusion, the effects of dietary fat modification on $\beta$-cell function were minor in the total study cohort, but in normoglycaemic subjects, the HMUFA diet was beneficial as compared to the HSFA diet. Further controlled studies should assess the possible effects of dietary fat modification on incretin-induced insulin secretion in subjects with a broad range of abnormalities in glucose metabolism.

\section{Declaration of interest}

Kåre I Birkeland is on the editorial board of EJE. Kåre I Birkeland was not involved in the review or editorial process for this paper, on which he is listed as an author. The other authors declare that there is no conflict of interest that could be perceived as prejudicing the impartiality of this study.

\section{Funding}

The study has been supported by LIPGENE - an EU $6^{\text {th }}$ Framework Program Integrated Project (FOOD-CT-2003-505944); the Norwegian Foundation for Health and Rehabilitation; South-Eastern Norway Regional Health Authority and the Norwegian Diabetic Association. Grants were also obtained from the Freia Chocolade Fabriks Medical Foundation, Direktør Johan Throne Holst Foundation for Nutrition Research, Norway. 


\section{Acknowledgements}

The authors thank the LIPGENE participants and the staff at all the clinical centers for their enthusiasm and support: Trinity College Dublin/University College Dublin, Ireland; University of Reading, UK; Oslo University Hospital Aker/University of Oslo, Norway; INSERM, Marseille, France; Maastricht University, The Netherlands; Hospital Universitario Reina Sofía/University of Córdoba, Spain; Jagiellonian Medical College, Krakow, Poland and Uppsala University, Sweden.

\section{References}

1 Cornier MA, Dabelea D, Hernandez TL, Lindstrom RC, Steig AJ, Stob NR, Van Pelt RE, Wang H \& Eckel RH. The metabolic syndrome. Endocrine Reviews 200829 777-822. (https://doi.org/10.1210/er.20080024)

2 Eckel RH, Alberti KG, Grundy SM \& Zimmet PZ. The metabolic syndrome. Lancet 2010375 181-183. (https://doi.org/10.1016/ S0140-6736(09)61794-3)

3 Kahn SE. Clinical review 135: the importance of beta-cell failure in the development and progression of type 2 diabetes. Journal of Clinical Endocrinology and Metabolism 200186 4047-4058. (https:// doi.org/10.1210/jcem.86.9.7713)

4 Lyssenko V, Almgren P, Anevski D, Perfekt R, Lahti K, Nissen M, Isomaa B, Forsen B, Homstrom N, Saloranta C et al. Predictors of and longitudinal changes in insulin sensitivity and secretion preceding onset of type 2 diabetes. Diabetes 200554 166-174. (https://doi. org/10.2337/diabetes.54.1.166)

5 Haffner SM, Miettinen H, Gaskill SP \& Stern MP. Decreased insulin secretion and increased insulin resistance are independently related to the 7-year risk of NIDDM in Mexican-Americans. Diabetes 199544 1386-1391. (https://doi.org/10.2337/diab.44.12.1386)

6 Kahn SE. The relative contributions of insulin resistance and beta-cell dysfunction to the pathophysiology of Type 2 diabetes. Diabetologia 200346 3-19. (https://doi.org/10.1007/s00125-002-1009-0)

7 Haffner SM, Miettinen H, Gaskill SP \& Stern MP. Decreased insulin action and insulin secretion predict the development of impaired glucose tolerance. Diabetologia 199639 1201-1207. (https://doi. org/10.1007/BF02658507)

8 Lillioja S, Mott DM, Spraul M, Ferraro R, Foley JE, Ravussin E, Knowler WC, Bennett PH \& Bogardus C. Insulin resistance and insulin secretory dysfunction as precursors of non-insulin-dependent diabetes mellitus. Prospective studies of Pima Indians. New England Journal of Medicine 1993329 1988-1992. (https://doi.org/10.1056/ NEJM199312303292703)

9 Uusitupa M, Lindi V, Louheranta A, Salopuro T, Lindstrom J, Tuomilehto J \& Finnish Diabetes Prevention Study Group. Long-term improvement in insulin sensitivity by changing lifestyles of people with impaired glucose tolerance: 4-year results from the Finnish Diabetes Prevention Study. Diabetes 200352 2532-2538. (https://doi. org/10.2337/diabetes.52.10.2532)

10 Knowler WC, Barrett-Connor E, Fowler SE, Hamman RF, Lachin JM, Walker EA, Nathan DM \& Diabetes Prevention Program Research Group. Reduction in the incidence of type 2 diabetes with lifestyle intervention or metformin. New England Journal of Medicine 2002346 393-403. (https://doi.org/10.1056/NEJMoa012512)

11 Tuomilehto J, Lindstrom J, Eriksson JG, Valle TT, Hamalainen H, Ilanne-Parikka P, Keinanen-Kiukaanniemi S, Laakso M, Louheranta A, Rastas $\mathrm{M}$ et al. Prevention of type 2 diabetes mellitus by changes in lifestyle among subjects with impaired glucose tolerance. New England Journal of Medicine 2001344 1343-1350. (https://doi. org/10.1056/NEJM200105033441801)

12 Orchard TJ, Temprosa M, Goldberg R, Haffner S, Ratner R, Marcovina S, Fowler S \& Diabetes Prevention Program Research Group. The effect of metformin and intensive lifestyle intervention on the metabolic syndrome: the Diabetes Prevention Program randomized trial. Annals of Internal Medicine 2005142 611-619. (https://doi.org/10.7326/0003-4819-142-8-200504190-00009)

13 Ilanne-Parikka P, Eriksson JG, Lindstrom J, Peltonen M, Aunola S, Hamalainen H, Keinanen-Kiukaanniemi S, Laakso M, Valle TT, Lahtela J et al. Effect of lifestyle intervention on the occurrence of metabolic syndrome and its components in the Finnish Diabetes Prevention Study. Diabetes Care 200831 805-807. (https://doi. org/10.2337/dc07-1117)

14 Astrup A, Ryan L, Grunwald GK, Storgaard M, Saris W, Melanson E $\&$ Hill JO. The role of dietary fat in body fatness: evidence from a preliminary meta-analysis of ad libitum low-fat dietary intervention studies. British Journal of Nutrition 200083 (Supplement 1) S25-S32. (https://doi.org/10.1017/S0007114500000921)

15 Riserus U, Willett WC \& Hu FB. Dietary fats and prevention of type 2 diabetes. Progress in Lipid Research 200948 44-51. (https://doi. org/10.1016/j.plipres.2008.10.002)

16 Riccardi G \& Rivellese AA. Dietary treatment of the metabolic syndrome-the optimal diet. British Journal of Nutrition 2000 83 (Supplement 1) S143-S148. (https://doi.org/10.1017/ S0007114500001082)

17 Weickert MO. What dietary modification best improves insulin sensitivity and why? Clinical Endocrinology 201277 508-512. (https:// doi.org/10.1111/j.1365-2265.2012.04450.x)

18 Manco M, Calvani M \& Mingrone G. Effects of dietary fatty acids on insulin sensitivity and secretion. Diabetes, Obesity and Metabolism 20046 402-413. (https://doi.org/10.1111/j.1462-8902.2004.00356.x)

19 Laaksonen DE, Toppinen LK, Juntunen KS, Autio K, Liukkonen KH, Poutanen KS, Niskanen L \& Mykkanen HM. Dietary carbohydrate modification enhances insulin secretion in persons with the metabolic syndrome. American Journal of Clinical Nutrition 200582 1218-1227. (https://doi.org/10.1093/ajcn/82.6.1218)

20 Vessby B, Uusitupa M, Hermansen K, Riccardi G, Rivellese AA, Tapsell LC, Nalsen C, Berglund L, Louheranta A, Rasmussen BM et al. Substituting dietary saturated for monounsaturated fat impairs insulin sensitivity in healthy men and women: the KANWU Study. Diabetologia 200144 312-319. (https://doi.org/10.1007/ s001250051620)

21 Rojo-Martinez G, Esteva I, Ruiz de Adana MS, Garcia-Almeida JM, Tinahones F, Cardona F, Morcillo S, Garcia-Escobar E, GarciaFuentes E \& Soriguer F. Dietary fatty acids and insulin secretion: a population-based study. European Journal of Clinical Nutrition $2006 \mathbf{6 0}$ 1195-1200. (https://doi.org/10.1038/sj.ejcn.1602437)

22 den Biggelaar LJCJ, Eussen SJPM, Sep SJS, Mari A, Ferrannini E, van Greevenbroek MM, van der Kallen CJ, Schalkwijk CG, Arts ICW, Stehouwer CDA et al. Prospective associations of dietary carbohydrate, fat, and protein intake with beta-cell function in the CODAM study. European Journal of Nutrition 2018. (https://doi. org/10.1007/s00394-018-1644-y)

23 Giacco R, Cuomo V, Vessby B, Uusitupa M, Hermansen K, Meyer BJ, Riccardi G, Rivellese AA \& KANWU Study Group. Fish oil, insulin sensitivity, insulin secretion and glucose tolerance in healthy people: is there any effect of fish oil supplementation in relation to the type of background diet and habitual dietary intake of n-6 and n-3 fatty acids? Nutrition, Metabolism, and Cardiovascular Diseases 200717 572-580. (https://doi.org/10.1016/j.numecd.2006.06.006)

24 Imamura F, Micha R, Wu JH, de Oliveira Otto MC, Otite FO, Abioye AI \& Mozaffarian D. Effects of saturated fat, polyunsaturated fat, monounsaturated fat, and carbohydrate on glucose-insulin homeostasis: A systematic review and meta-analysis of randomised controlled feeding trials. PLOS Medicine 201613 e1002087. (https:// doi.org/10.1371/journal.pmed.1002087)

25 Altman DG \& Bland JM. Treatment allocation by minimisation. BMJ 2005330 843. (https://doi.org/10.1136/bmj.330.7495.843)

26 Tierney AC, McMonagle J, Shaw DI, Gulseth HL, Helal O, Saris WH, Paniagua JA, Golabek-Leszczynska I, Defoort C, Williams CM et al. 
Effects of dietary fat modification on insulin sensitivity and on other risk factors of the metabolic syndrome--LIPGENE: a European randomized dietary intervention study. International Journal of Obesity 201135 800-809. (https://doi.org/10.1038/ijo.2010.209)

27 Expert Panel on Detection, Evaluation, and Treatment of High Blood Cholesterol in Adults. Executive summary of the third report of the National Cholesterol Education Program (NCEP) Expert Panel on Detection, evaluation, and treatment of high blood cholesterol in adults (Adult Treatment Panel III). JAMA 2001285 2486-2497. (https://doi.org/10.1001/jama.285.19.2486)

28 Shaw DI, Tierney AC, McCarthy S, Upritchard J, Vermunt S, Gulseth HL, Drevon CA, Blaak EE, Saris WH, Karlstrom B et al. LIPGENE food-exchange model for alteration of dietary fat quantity and quality in free-living participants from eight European countries. British Journal of Nutrition 2009101 750-759. (https://doi. org/10.1017/S0007114508039962)

29 Baecke JA, Burema J \& Frijters JE. A short questionnaire for the measurement of habitual physical activity in epidemiological studies. American Journal of Clinical Nutrition 198236 936-942. (https://doi. org/10.1093/ajcn/36.5.936)

30 Mansia G, De Backer G, Dominiczak A, Cifkova R, Fagard R, Germano G, Grassi G, Heagerty AM, Kjeldsen SE, Laurent S et al. 2007 ESH-ESC Guidelines for the management of arterial hypertension: the task force for the management of arterial hypertension of the European Society of Hypertension (ESH) and of the European Society of Cardiology (ESC). Blood Pressure 200716 135-232. (https://doi.org/10.1080/08037050701461084)

31 Steil GM, Volund A, Kahn SE \& Bergman RN. Reduced sample number for calculation of insulin sensitivity and glucose effectiveness from the minimal model. Suitability for use in population studies. Diabetes 199342 250-256. (https://doi. org/10.2337/diab.42.2.250)

32 Boston RC, Stefanovski D, Moate PJ, Sumner AE, Watanabe RM \& Bergman RN. MINMOD Millennium: a computer program to calculate glucose effectiveness and insulin sensitivity from the frequently sampled intravenous glucose tolerance test. Diabetes Technology and Therapeutics 20035 1003-1015. (https://doi. org/10.1089/152091503322641060)

33 Vickers AJ \& Altman DG. Statistics notes: analysing controlled trials with baseline and follow up measurements. BMJ 2001323 1123-1124. (https://doi.org/10.1136/bmj.323.7321.1123)

34 Fasching P, Ratheiser K, Schneeweiss B, Rohac M, Nowotny P \& Waldhausl W. No effect of short-term dietary supplementation of saturated and poly- and monounsaturated fatty acids on insulin secretion and sensitivity in healthy men. Annals of Nutrition and Metabolism 199640 116-122. (https://doi.org/10.1159/000177904)
35 Larsson H, Elmstahl S, Berglund G \& Ahren B. Habitual dietary intake versus glucose tolerance, insulin sensitivity and insulin secretion in postmenopausal women. Journal of Internal Medicine 1999245 581-591. (https://doi.org/10.1046/j.13652796.1999.00503.x)

36 Godsland IF, Jeffs JAR \& Johnston DG. Loss of beta cell function as fasting glucose increases in the non-diabetic range. Diabetologia 2004 47 1157-1166. (https://doi.org/10.1007/s00125-004-1454-z)

37 Mari A, Tura A, Pacini G, Kautzky-Willer A \& Ferrannini E. Relationships between insulin secretion after intravenous and oral glucose administration in subjects with glucose tolerance ranging from normal to overt diabetes. Diabetic Medicine 200825 671-677. (https://doi.org/10.1111/j.1464-5491.2008.02441.x)

38 Thomsen C, Rasmussen O, Lousen T, Holst JJ, Fenselau S, Schrezenmeir J \& Hermansen K. Differential effects of saturated and monounsaturated fatty acids on postprandial lipemia and incretin responses in healthy subjects. American Journal of Clinical Nutrition 199969 1135-1143. (https://doi.org/10.1093/ ajcn/69.6.1135)

39 Lopez S, Bermudez B, Pacheco YM, Villar J, Abia R \& Muriana FJ. Distinctive postprandial modulation of beta cell function and insulin sensitivity by dietary fats: monounsaturated compared with saturated fatty acids. American Journal of Clinical Nutrition $2008 \mathbf{8 8}$ 638-644. (https://doi.org/10.1093/ajcn/88.3.638)

40 Beysen C, Karpe F, Fielding BA, Clark A, Levy JC \& Frayn KN. Interaction between specific fatty acids, GLP-1 and insulin secretion in humans. Diabetologia 200245 1533-1541. (https://doi. org/10.1007/s00125-002-0964-9)

41 Rocca AS, LaGreca J, Kalitsky J \& Brubaker PL. Monounsaturated fatty acid diets improve glycemic tolerance through increased secretion of glucagon-like peptide-1. Endocrinology 2001142 1148-1155. (https:// doi.org/10.1210/endo.142.3.8034)

42 Cnop M, Abdulkarim B, Bottu G, Cunha DA, Igoillo-Esteve M, Masini M, Turatsinze JV, Griebel T, Villate O, Santin I et al. RNA sequencing identifies dysregulation of the human pancreatic islet transcriptome by the saturated fatty acid palmitate. Diabetes 201463 1978-1993. (https://doi.org/10.2337/db13-1383)

43 Cunha DA, Hekerman P, Ladriere L, Bazarra-Castro A, Ortis F, Wakeham MC, Moore F, Rasschaert J, Cardozo AK, Bellomo E et al. Initiation and execution of lipotoxic ER stress in pancreatic beta-cells. Journal of Cell Science 2008121 2308-2318. (https://doi. org/10.1242/jcs.026062)

44 Beard JC, Bergman RN, Ward WK \& Porte D Jr. The insulin sensitivity index in nondiabetic man. Correlation between clamp-derived and IVGTT-derived values. Diabetes 198635 362-369. (https://doi. org/10.2337/diab.35.3.362)

Received 9 January 2019

Revised version received 14 March 2019

Accepted 20 March 2019 